\title{
Do floral traits and the selfing capacity of Mimulus guttatus plastically respond to experimental temperature changes?
}

\author{
Mialy Razanajatovo ${ }^{1}$ [D $\cdot$ Liliana Fischer ${ }^{1}$ Mark van Kleunen ${ }^{1,2}$
}

\begin{abstract}
Climate change can negatively impact plant-pollinator interactions, and reduce outcross pollination. For reproductive assurance, an increased capacity for autonomous selfing should benefit the persistence of plants under new temperature conditions. Plastic responses of the autonomous selfing capacity to climate change may occur indirectly due to changes in floral traits associated with this capacity. We tested whether the mixed mating plant Mimulus guttatus is capable of plastic changes in floral traits favoring autonomous selfing in response to temperature changes. In seven growth chambers, we grew $M$. guttatus originating from a large range of latitudes (from $37.89^{\circ} \mathrm{N}$ to $49.95^{\circ} \mathrm{N}$ ) and thus home temperatures in North America, and experimentally assessed the (autonomous) selfing and outcrossing capacities of the plants. With an increase in the difference between the overall mean daytime and nighttime experimental test temperature and home temperature, flower length and width decreased. The plastic response in flower size suggests that plants may be more successful at autonomous selfing. However, we did not find direct evidence that M. guttatus responded to increased temperature by an increased autonomous selfing capacity. With an increase in temperature difference, the odds of seed production, number of seeds, and individual seed mass decreased. Our results indicate that global warming and the associated increase in extreme temperature events may be detrimental to the reproduction and thus persistence of some plants.
\end{abstract}

Keywords Autofertility $\cdot$ Breeding system $\cdot$ Global change $\cdot$ Herkogamy $\cdot$ Phenotypic plasticity

\section{Introduction}

Due to a rapidly changing climate, many organisms experience novel environmental conditions (IPCC 2014). Recent climate change scenarios predict widespread warming over the world's land surfaces and an increased frequency of extreme high temperature events (IPCC 2013). Most notably, plants and animals have responded to climate change

Communicated by Amy Parachnowitsch.

Mialy Razanajatovo

mialy.razanajatovo@uni-konstanz.de

1 Ecology, Department of Biology, University of Konstanz, Universitätsstrasse 10, 78457 Constance, Germany

2 Zhejiang Provincial Key Laboratory of Plant Evolutionary Ecology and Conservation, Taizhou University, Taizhou 318000, China by advancing the timing of their seasonal activities (Cohen et al. 2018; Parmesan 2006; Parmesan and Yohe 2003; Razanajatovo et al. 2018). Particularly, plants have shown complex patterns of responses to climate change in phenology, ecophysiology, reproduction, species interactions and distributions (Parmesan and Hanley 2015). Because of possible asynchronies between flowering and pollinator activity, phenological shifts may negatively affect plant-pollinator interactions (Memmott et al. 2007). Furthermore, insects can respond to climate change with shrinking body sizes, which can also negatively affect plant-pollinator interactions (Sheridan and Bickford 2011). Disruption of plant-pollinator interactions may have detrimental effects on the reproduction of animal-pollinated plants, and thus on the persistence of populations under climate change (Burkle et al. 2013).

Rapid plastic responses, as opposed to a relatively long period of genetic adjustment (i.e., response to selection) after multigenerational selection, have been suggested to facilitate the initial survival of populations under the new conditions (Chevin and Hoffmann 2017; Ghalambor et al. 2007; Nicotra 
et al. 2010). If plant-pollinator interactions are disrupted due to climate change or if pollinators and thus pollinator shifts become scarce, plastic changes in autonomous selfing capacity might become important to assure reproduction. Indeed, plasticity in the capacity for autonomous selfing, including a weakened self-incompatibility and an increased capacity for selfing, has been documented in various species from many plant families including Poaceae, Liliaceae, Convolvulaceae, Brassicaceae, Solanaceae and Asteraceae (Levin 2010) in response to a decrease in pollinator activity (Brys et al. 2013; Bodbyl Roels and Kelly 2011; Travers et al. 2004; Vogler et al. 1998).

An increased capacity for selfing is expected to be advantageous for the persistence of plants in harsh conditions for various reasons. According to the time-limitation hypothesis, if harsh conditions increase mortality risk in mother plants and severely restrict fecundity to a short period, an increased selfing should allow for a shorter time between flower maturation and ovule fertilization, because plants do not have to spend time waiting for pollinators (Aarssen 2000; Spigler and Kalisz 2013). According to the reproductive assurance hypothesis, autonomous selfing (i.e., ovules fertilized by pollen from the same flower without requiring a pollinator) should guarantee seed production when opportunities for cross-pollination are scarce because of a lack of mates or pollinators (Eckert et al. 2010; Herlihy and Eckert 2002; Kalisz et al. 2004; Levin 2010). Moreover, extreme temperatures and drought have been associated with an increased selfing in general (Evans et al. 2011). Therefore, increased autonomous selfing should be advantageous for the persistence of plants under the new temperature conditions that characterize climate change.

The capacity for autonomous selfing may be affected by different environmental stressors. Under climate change, the average surface temperature of the entire globe is projected to increase, whereas changes in precipitation will not be uniform, with some areas exposed to increased precipitation and others to drier conditions (IPCC 2014). In particular, even when precipitation is not affected, high temperatures might increase evapotranspiration and thereby cause drought stress. Drought has been shown to increase the capacity for autonomous selfing in some species (Ivey and Carr 2011; Kay and Picklum 2013; Spigler and Kalisz 2013). The capacity for autonomous selfing can also increase when plants are exposed to high temperatures within the range that they may experience in nature (Ascher and Peloquin 1966; Levin 2010). Nevertheless, few studies have tested whether increases in average temperature by $3-4{ }^{\circ} \mathrm{C}$, or even more extreme heat events, as forecasted by climate change scenarios for 2100 (IPCC 2013), will result in a higher capacity for autonomous selfing in plants (Jones et al. 2013).

Plastic responses of the capacity for autonomous selfing to climate change may occur indirectly due to changes in floral traits associated with this capacity (Levin 2010). Because the female and male parts of the flowers are more likely to be in contact within small flowers, a reduced flower size has been associated with high selfing rates (Sicard and Lenhard 2011). A short distance separating the anther and the stigma can increase the number of ovules fertilized by pollen from the same flower by autonomous selfing (Lloyd and Schoen 1992). Therefore, a reduced anther-stigma separation has also been associated with increased autonomous selfing (Eckert et al. 2009; Elle and Hare 2002; Herlihy and Eckert 2002; Vallejo-Marín and Barrett 2009; van Kleunen and Ritland 2004). Both small flowers and a reduced anther-stigma separation have been associated with the capacity for autonomous selfing in M. guttatus (Lekberg et al. 2012). A reduced anther-stigma separation can also be a common response to abiotic environmental stress (e.g., van Kleunen 2007). Further, the temporal separation of male and female sexual functions (dichogamy) can have a pronounced variation among populations (Leibman et al. 2018), and a reduction in dichogamy may be associated with an increased autonomous selfing due to a maximized overlap in sexual phases (Koski et al. 2018). So, because an increase in temperature can induce plastic changes in floral traits, we may expect climate change to have an effect on a plant's capacity for autonomous selfing (Van Etten and Brunet 2013). However, few studies have looked at the effect of climate change, especially that of temperature changes, on floral traits associated with autonomous selfing.

Here, we tested whether $M$. guttatus is capable of rapid plastic responses in floral traits favoring autonomous selfing under experimental temperature changes. Mimulus guttatus has a broad geographic range as it is native to western North America, and naturalized in several regions, including eastern North America, Europe and New Zealand (van Kleunen et al. 2019). Moreover, it has a mixed mating system, i.e., it can reproduce predominantly by outcrossing when pollinators are abundant, but can also largely reproduce by selfing when the opportunities for outcrossing are scarce (Fenster and Ritland 1994; Leclerc-Potvin and Ritland 1994). To capture the variability in floral traits and capacity for autonomous selfing among different populations and to increase the generality of the results (van Kleunen et al. 2014), we used multiple populations of $M$. guttatus originating from a large range of latitudes (from $37.89^{\circ} \mathrm{N}$ to $49.95^{\circ} \mathrm{N}$ ) and thus home temperatures in its native range in North America. As climate change is predicted to affect different parts of the species range differently, sampling populations across the range allows controlling for variations due to population origin. Specifically, we asked:

1. Do flower size (length and width) and anther-stigma separation in M. guttatus decrease when temperature increases? 
2. Does the capacity for autonomous selfing in M. guttatus increase when temperature increases?

\section{Methods}

\section{Study species and plant materials}

\section{Study species}

The yellow monkey flower Mimulus guttatus Fisch. ex DC. (Phrymaceae) is an annual or perennial herb native to western North America, and has been introduced as a garden plant and become naturalized in several regions, including eastern North America, Europe and New Zealand (van Kleunen et al. 2019). The species usually grows in moist habitats such as streams, ditches, wet grasslands and on wet bluffs along the sea (van Kleunen 2007). The hermaphroditic tubular flowers are zygomorphic, i.e., have a bilateral symmetry, and include two pairs of anthers of different lengths and a pistil which ends in a two-lobed stigma. In the Northern Hemisphere, M. guttatus usually flowers from May to September. The flowers are pollinated by bumblebees and other bees, and produce almost no nectar (Robertson et al. 1999). Mimulus guttatus has a mixed mating system, and autonomous selfing can take place when the lower lobe of the stigma curls into the anthers and touches the pollen, or when the corolla and the attached stamen abscise and brush the stigma (Dole 1992). The fruit capsule can contain up to 1000 small seeds. The species can also reproduce vegetatively by producing stolons that can root at the nodes.

\section{Plant materials}

To test the plasticity of the capacity for autonomous selfing in M. guttatus under temperature change, we used seeds representing seven populations in western North America (Table S1). Seeds had been collected in these populations in 2002 and 2003. To get rid of differences due to maternal carryover effects, we first grew one generation of plants of these populations in a greenhouse, and made hand-crosses between plants of the same populations in 2012 to create the seeds from which we grew the plants used in the study described here (for details, see van Kleunen et al. 2015). Our plant materials covered a large range of climatic conditions of population origin, from a population in the US state of California $\left(37.89^{\circ} \mathrm{N}\right)$ to a population in the Canadian province of British Columbia $\left(49.95^{\circ} \mathrm{N}\right)$. On 05-Apr-2016, we sowed seeds of seven seed families from each of the seven study populations in a climate chamber at the University of Konstanz, Germany. We germinated the seeds at a day temperature of $22{ }^{\circ} \mathrm{C}$, a night temperature of $18{ }^{\circ} \mathrm{C}$ and a light period of $11 \mathrm{~h}$. On 18-Apr-2016, we transplanted seven seedlings from each of four to five seed families from each population (a total of 231 seedlings) into $0.2 \mathrm{~L}$ pots filled with commercial potting soil (Einheitserde Sinntal-Altengronau, Germany). We placed one seedling of each seed family in each of seven growth chambers (33 seedlings per chamber). This way, we had the same genetic material in each of the seven growth chambers. We let the plants grow at $22{ }^{\circ} \mathrm{C}$ and a light period of $14 \mathrm{~h}$ until 27-Apr-2016, when we started the temperature treatments.

\section{Experimental setup and measurements}

\section{Temperature treatments}

To test whether M. guttatus is capable of rapid plastic responses in floral traits associated with autonomous selfing under increased temperature, we manipulated the air temperature under which the plants were grown using seven pollinator-free growth chambers. We used those seven chambers to create a temperature gradient according to the average home temperatures for May and June of the different populations from which the seeds originated (Table S2). To obtain constant intervals of temperature increase for daytime and nighttime temperatures, we set the mean daytime temperature of each population location to increase with $3{ }^{\circ} \mathrm{C}$, and night time temperature with $1{ }^{\circ} \mathrm{C}$ (Table S3). We started the treatment temperatures on 27-Apr-2016, i.e., approximately 2 weeks before the onset of flowering. To record the realized treatment temperature throughout the experiment, we placed one iButton data logger in each growth chamber, which we programmed to record the air temperature every hour. To minimize effects on plant growth due to variation in growing conditions within each growth chamber, we randomized the position of the pots once a week. To keep the soil of the plants continuously moist, we watered the plants as needed.

\section{Floral trait measurements}

To assess plastic responses of floral traits associated with autonomous selfing in M. guttatus, we measured flower size (length and width) and anther-stigma separation. We measured flower length as the distance between the base of the calyx and the upper end of the lower lip of the flower, i.e., the longest distance to the calyx (Fig. 1a). We measured flower width as the widest distance on the lower lip of the flower (Fig. 1b). We measured anther-stigma separation as the distance between the tip of the stigma and the tip of the anthers on the longest pair of stamens (Fig. 1c). For each plant, each measurement was done on one flower in full bloom that did not show any signs of senescence, and that was located above the third stem node carrying flowers. As not all plants flowered or had sufficient numbers of flowers, 

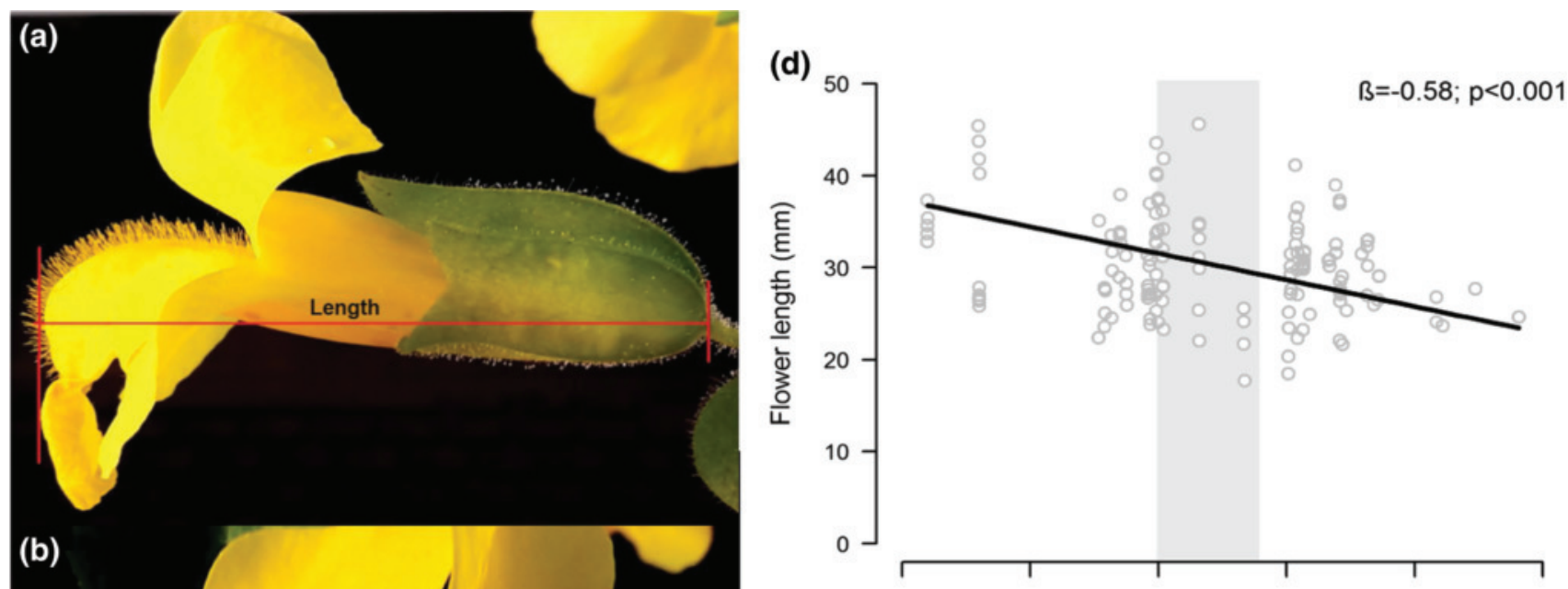

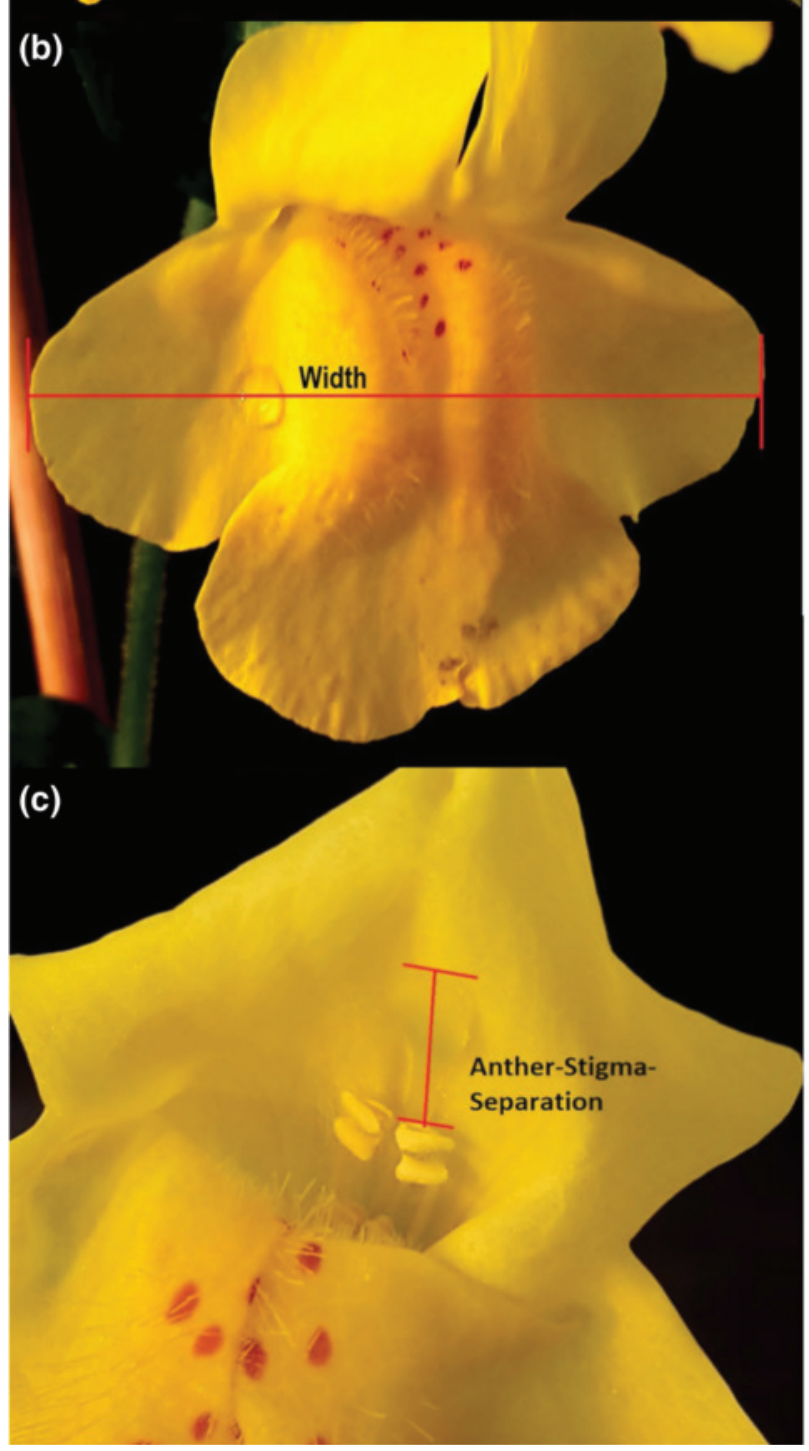

Fig. 1 Images of Mimulus guttatus showing how traits included in the models were measured and results of three linear mixed models testing how these traits depend on the temperature difference between the experimental test temperature and the home temperature of source
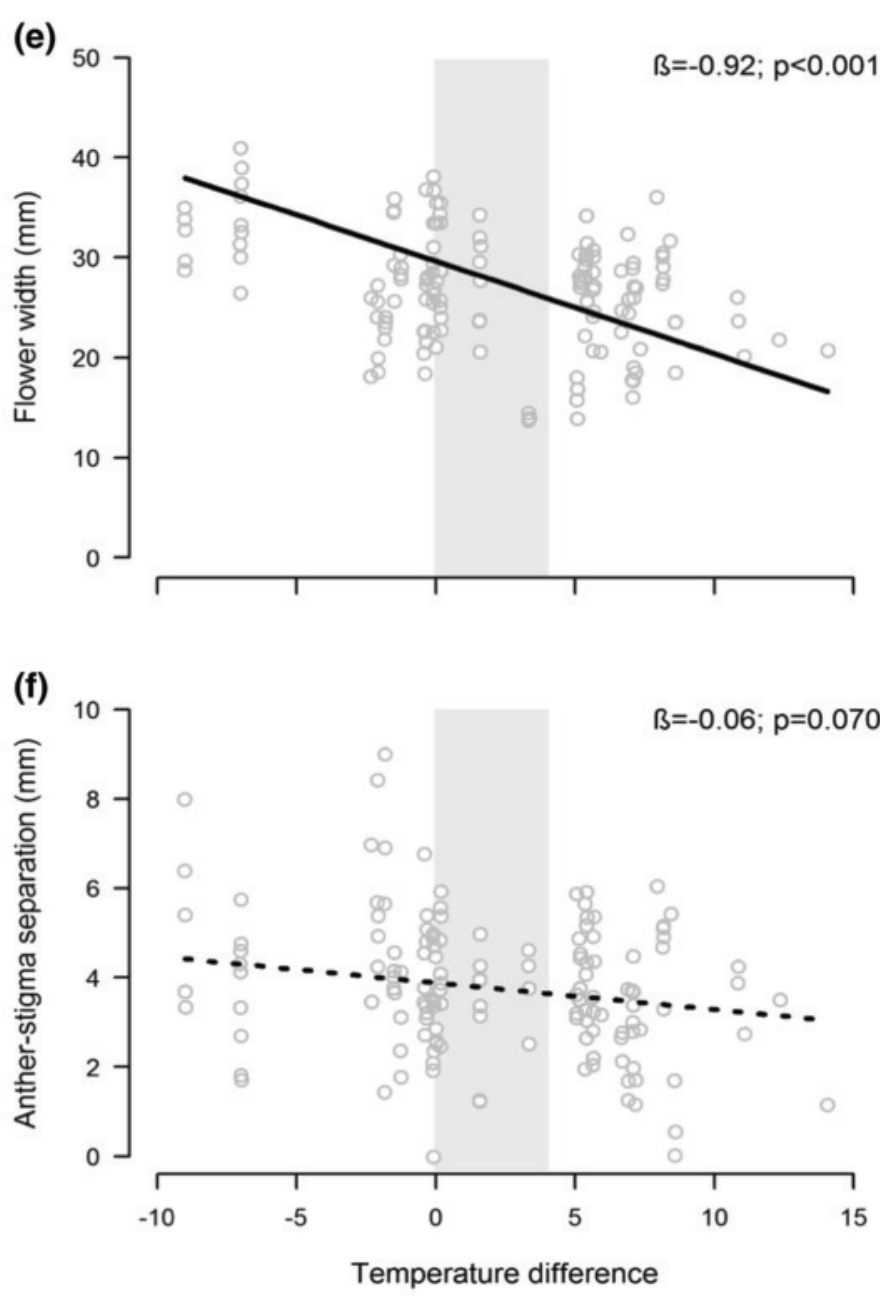

populations. a, d Flower length, b, e flower width and $\mathbf{c}, \mathbf{f}$ antherstigma separation. Shaded areas represent up to $4{ }^{\circ} \mathrm{C}$ temperature increase as predicted by the IPCC for 2100 . Gray circles represent raw data points. Statistics are regression slope (ß) and $p$ value 
floral trait measurements could be done on only 140 of the 231 plants.

\section{Breeding-system treatments}

To assess the capacity for autonomous selfing, selfing and outcrossing of the $M$. guttatus plants in the different temperature treatments, we did three breeding-system treatments (Kearns and Inouye 1993). Out of the 231 plants grown in the seven growth chambers, 173 plants flowered (flowering was related to population origin and temperature treatment; Figs. S1, S2) and were treated with one or more breedingsystem treatments. First, to assess the capacity for autonomous selfing, we marked a flower on each plant and left it untouched (i.e., not hand-pollinated; hereafter, the "early" autonomous selfing). In addition, to assess whether the capacity for autonomous selfing changes with the developmental stage of the plants, we marked additional flowers which developed 16 weeks after the plants had been transplanted, i.e., later than the flowers used for the autonomous selfing treatment (hereafter, the "late" autonomous selfing). Second, to assess the degree of self-compatibility of the plants, we marked and hand-pollinated a flower with pollen from the same plant. Third, to assess maximal seed production after outcrossing, we marked and hand-pollinated a flower with outcross pollen from the same population and grown in the same growth chamber. As we did not emasculate the flowers before the treatment, there might also be autonomous selfing of these flowers, and the outcrossing treatment is therefore equivalent to supplemental hand pollination. In total, we treated 465 flowers, including 172 flowers in the early autonomous selfing treatment, 23 flowers in the late autonomous selfing treatment, 146 flowers in the selfing treatment and 124 flowers in the outcrossing treatment.

We collected the fruit capsules when their peduncles looked desiccated, and the capsules were stored in paper bags at room temperature. To assess seed production in each breeding-system treatment, we weighed the total seeds produced in a capsule and a subset of 20 seeds. We used these data to calculate the number of seeds and the average individual seed mass. If a capsule contained fewer than 20 seeds, we counted them directly, but still weighed them to determine the average individual seed mass.

\section{Statistical analysis}

\section{The effect of temperature change on floral traits associated with autonomous selfing}

To quantify for each population the change in temperature achieved by the temperature treatments in our study, we calculated the temperature difference between the mean temperature in each experimental temperature treatment (Table S3) and the mean May-June home temperature of the population (Table S2). To test whether flower size and anther-stigma separation decreased under warmer experimental conditions, we fitted three linear mixed models using the lmer function of the lme4 package (Bates et al. 2015) in $\mathrm{R}$ ( $\mathrm{R}$ Core Team 2012). As response variables, we used flower length, flower width and anther-stigma separation. Because each temperature treatment corresponded to one growth chamber, we did not have replicates for each temperature regime. To avoid that the results would be subject to pseudoreplication (Colegrave and Ruxton 2017), we did not include growth chamber as a factor with seven levels as an explanatory variable. Instead, we included the temperature difference between the experiment temperature and the home temperature as a continuous covariable. In addition, to account for non-independence of observations within each growth chamber, we included growth chamber as a random factor. To account for non-independence of observations from the same seed family and from the same population, we also included population and seed family nested within population as random factors. We checked model assumptions with residual plots.

\section{The effect of temperature change on the capacity for autonomous selfing}

To test whether autonomous selfing increased in warmer experimental conditions, we fitted a logistic regression and two linear mixed models using the glmer and lmer functions of the lme 4 package in R. To compare the reproductive output after the three breeding-system treatments, our response variables were seed production yes or no (binomial distribution), the number of seeds produced per capsule, and the individual seed mass in milligram. The number of seeds produced and the individual seed mass were square root transformed to ensure a Gaussian distribution of the residuals. As explanatory variables, we included the temperature difference between the experiment temperature and the home temperature (i.e., a continuous covariable), breeding-system treatment, and the interaction between temperature difference and breeding-system treatment. Because the likelihood of seed production was not significantly different between the "early" and the "late" autonomous selfing treatments $(n=195, p=0.063$, Table S4), we merged both autonomous selfing treatments, and considered them as one breeding-system treatment in the analysis: the autonomous selfing treatment. We also included growth chamber, plant individual nested within seed family, seed family nested within population and population as random factors in these models. In the models with the number of seed produced per capsule and the individual seed mass, we analyzed the subset of observations in which seeds were produced $(n=257)$. We 
tested for significance of the fixed terms using log-likelihood ratio tests (Zuur et al. 2009). We checked model assumptions for the linear mixed models with residual plots.

To additionally quantify the degree of autonomous selfing of plants under the different experimental temperatures, we calculated an index of autonomous selfing (ASI) for individual plants (Eckert et al. 2010) as

$\mathrm{ASI}=\frac{\text { number of seeds from autonomous selfing treatment }}{\text { number of seeds from outcross treatment }}$.

In the calculation of ASI, we used the number of seeds from the "early" autonomous selfing treatment $(n=99)$, and only used data from the "late" autonomous selfing treatment when the latter was lacking $(n=1)$. To be able to use statistical methods that accommodate values in the interval zero and one, we set ASI values larger than one to one (values set to one were $5 \%$ of observations). To test whether the degree of autonomous selfing increased under warmer experimental conditions, we fitted a zero-and-one-inflated beta regression model (Liu and Eugenio 2018) using the zoib package (Liu and Kong 2015) in R, with ASI as a response variable. As an explanatory variable, we included the temperature difference between the experiment temperature and the home temperature. The explanatory variable was also included in the zero- and one-inflation parts of the model. As a random factor, we also included growth chamber in the model.

To test whether the degree of autonomous selfing is related to floral traits, we also fitted three zero-and-oneinflated beta regression models, with ASI as a response variable. As explanatory variables, we included flower length, flower width and anther-stigma separation, respectively. The explanatory variables were also included in the zero-andone-inflation parts of the models. As a random factor, we included growth chamber in the models.

\section{Results}

\section{The effect of temperature change on floral traits associated with autonomous selfing}

The temperature difference between experimental test temperature and home temperature ranged from $-9.0^{\circ} \mathrm{C}$ to $+14.0^{\circ} \mathrm{C}$, with a median of $+1.5^{\circ} \mathrm{C}$ (i.e., some plants experienced cooling in comparison to their home temperature, $n=65$ ). When the temperature difference increased, flower length and width significantly decreased (Fig. 1; Table 1). For every increase of $1{ }^{\circ} \mathrm{C}$ in the temperature difference between experimental test temperature and home temperature, flower length (mean $=30.70 \mathrm{~mm}$, Table S5) and width (mean $=27.47 \mathrm{~mm}$, Table S5) decreased by $0.57 \mathrm{~mm}$ and $0.92 \mathrm{~mm}$, respectively (Fig. 1). When the temperature difference increased, anther-stigma separation (mean $=3.79 \mathrm{~mm}$, Table S5) tended to decrease (Fig. 1), but this effect was marginally non-significant (Table 1). For every increase of $1{ }^{\circ} \mathrm{C}$ in the temperature difference between experimental test temperature and home temperature, the anther-stigma separation tended to decrease with $0.06 \mathrm{~mm}$ (Fig. 1).

\section{The effect of temperature change on the capacity for autonomous selfing}

Out of 465 treated flowers, 257 (55.3\%) set seeds across the breeding-system treatments, 38 out of 195 flowers (19.5\%) in the autonomous selfing treatment, 119 out of $146(81.5 \%)$ in the manual selfing treatment, and 100 out of $124(80.6 \%)$ in the manual outcrossing treatment. Across the seven growth chambers (i.e., temperature treatments), Mimulus guttatus set seeds in all three breeding-system treatments (i.e., autonomous selfing, selfing and outcrossing), but the likelihood of seed production (yes, no), seed number and individual seed mass were on average significantly lower in the autonomous selfing treatment than in the selfing and outcrossing treatments (Fig. 2, Table 2). Regardless of breeding-system treatments, when the temperature difference increased, the
Table 1 Results of three linear mixed models testing how flower length, flower width and anther-stigma separation in Mimulus guttatus depend on the temperature difference between the experimental test temperature and the home temperature of the population

\begin{tabular}{|c|c|c|c|c|c|c|c|c|c|}
\hline \multirow{2}{*}{$\begin{array}{l}\text { Response variable } \\
\text { Explanatory and random variables }\end{array}$} & \multicolumn{3}{|c|}{ Flower length } & \multicolumn{3}{|c|}{ Flower width } & \multicolumn{3}{|c|}{$\begin{array}{l}\text { Anther-stigma } \\
\text { separation }\end{array}$} \\
\hline & $d f$ & $\chi^{2}$ & $p$ & $d f$ & $\chi^{2}$ & $p$ & $d f$ & $x^{2}$ & $p$ \\
\hline Temperature difference & 1 & 12.27 & $<0.001$ & 1 & 14.06 & $<0.001$ & 1 & 3.29 & 0.070 \\
\hline Growth chamber & & & 0.786 & & & 0.725 & & & 0.269 \\
\hline Population & & & 4.137 & & & 5.422 & & & 0.835 \\
\hline Seed family & & & 0.546 & & & $<0.001$ & & & 0.749 \\
\hline Residuals & & & 3.529 & & & 3.133 & & & 1.065 \\
\hline
\end{tabular}

Random variables include growth chamber, population and seed family. Standard deviations are provided for random variables 


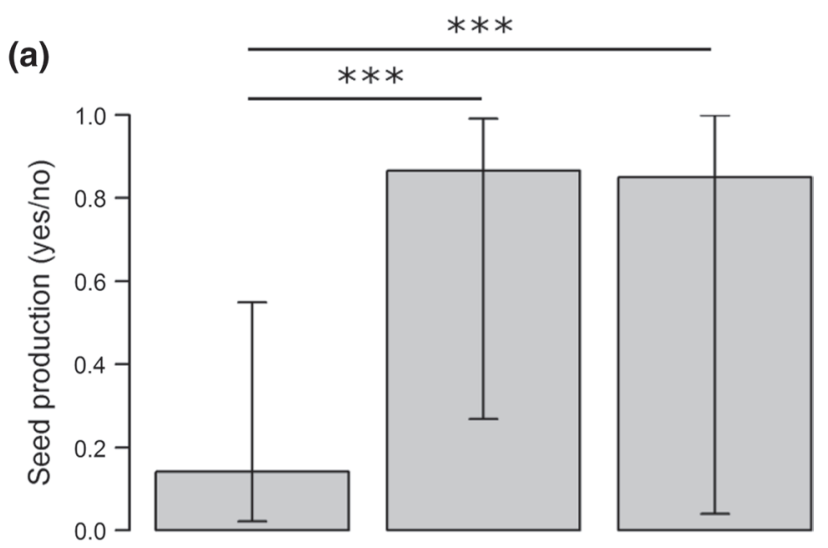

(b)
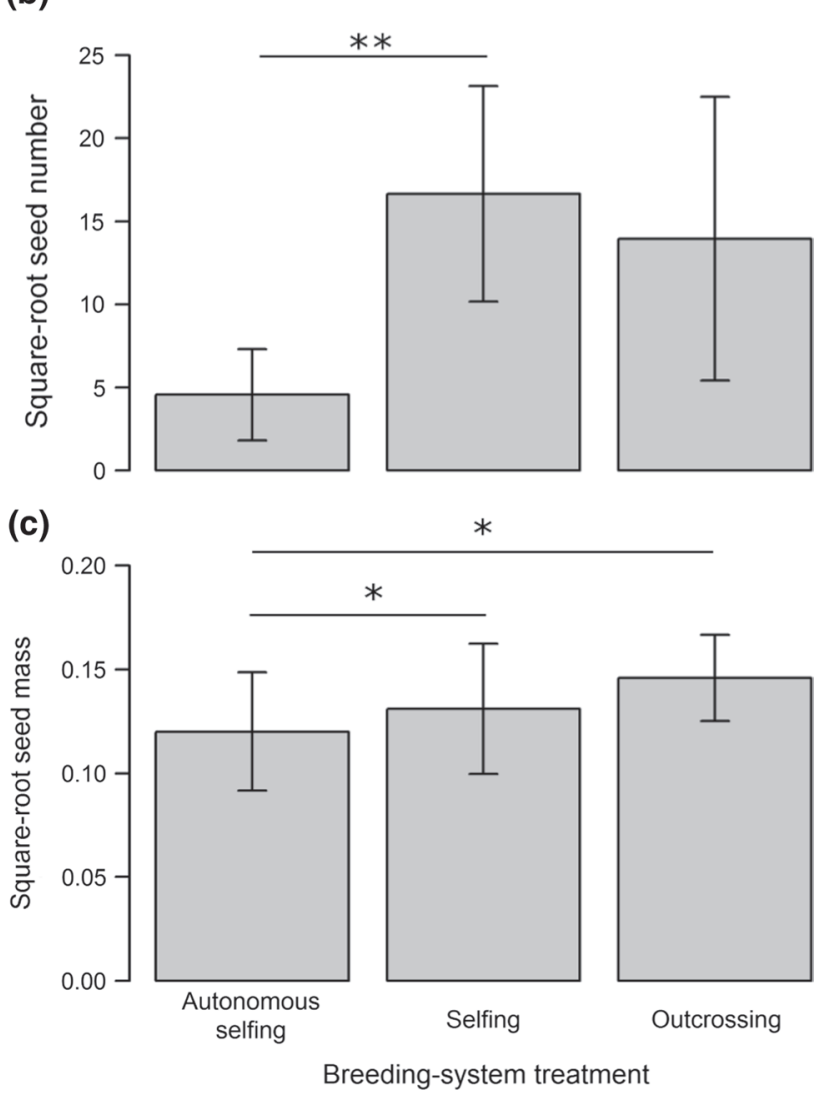

Fig. 2 The effect of breeding-system treatments on a seed production (yes/no), b the square root seed number and $\mathbf{c}$ the square root individual seed mass (mg) in Mimulus guttatus across seven temperature treatments. Model estimates and 95\% confidence intervals from a logistic regression (back transformed means) and two linear mixed models. Asterisks show $* * * p<0.001, * * 0.001<p<0.01, * 0.01<p$ $<0.05$

likelihood of seed production, seed number and individual seed mass decreased on average (Fig. 3, Table 1). For every increase of $1{ }^{\circ} \mathrm{C}$ in the temperature difference between experimental test temperature and home temperature, the odds of seed production decreased by a factor of 1.2 , the square root of the number of seeds produced decreased by $6 \%$ and the square root of the individual seed mass decreased by $25 \%$ (Table 2). The decrease in the likelihood of seed production when temperature difference increased was stronger in the selfing and outcrossing treatments than in the autonomous selfing treatment (Fig. 3), as indicated by a significant interaction between breeding-system treatment and temperature difference between experiment temperature and home temperature (Table 2).

For 100 individual plants, we had data available for both autonomous selfing and outcrossing treatments to calculate the index of autonomous selfing (ASI). For plants with intermediate values of ASI (i.e., $0<$ ASI $<1$ ), the degree of autonomous selfing was not related to experimental temperature change (Table 3). However, when the temperature difference between experimental and home temperature increased, a total absence of the capacity for autonomous selfing was more likely (ASI $=0$; Table 3 ).

For 94 individual plants, we had data on both the index of autonomous selfing and floral traits (i.e., flower length and width, and anther-stigma separation). When flower length and width increased, a total absence of autonomous selfing was less likely (ASI $=0$; Table 4). For plants with intermediate values of ASI (i.e., $0<\mathrm{ASI}<1$ ), an increase in anther-stigma separation corresponded to a decrease in the degree of autonomous selfing (Table 4).

\section{Discussion}

Here, we showed that when temperature increased, flower size of M. guttatus decreased, and there was a trend of decreasing anther-stigma separation. However, although these floral traits are typical of the selfing syndrome (Sicard and Lenhard 2011), we did not find direct evidence that $M$. guttatus plastically responded to increased temperature by an increased capacity for autonomous selfing. Overall, warmer temperature conditions decreased the likelihood of seed production, seed number and seed mass in all breeding-system treatments (Fig. 3), indicating that severe climate change may decrease sexual reproduction of M. guttatus.

\section{Flower size decreased and anther-stigma separation tended to decrease when temperature increased}

In line with previous findings showing decreased flower size and anther-stigma separation under stressful environmental conditions, flower length and width decreased when temperature increased, and there was a trend of decreasing anther-stigma separation in our study (Fig. 1; Table 1). Most previous studies investigating floral plasticity under environmental change considered soil moisture and showed 
Table 2 Results of a logistic regression and two linear mixed models testing how seed production, seed number and individual seed mass in Mimulus guttatus depend on the temperature difference between the experimental test temperature and the home temperature, breeding-system treatment and the interaction between the temperature difference and breeding-system treatment

\begin{tabular}{|c|c|c|c|c|c|c|c|c|c|}
\hline \multirow{2}{*}{$\begin{array}{l}\text { Response variable } \\
\text { Explanatory and random variables }\end{array}$} & \multicolumn{3}{|c|}{ Seed production } & \multicolumn{3}{|c|}{ Seed number } & \multicolumn{3}{|c|}{ Individual seed mass } \\
\hline & $d f$ & $\chi^{2}$ & $p$ & $d f$ & $\chi^{2}$ & $p$ & $d f$ & $\chi^{2}$ & $p$ \\
\hline Breeding-system treatment & 2 & 205.94 & $<0.001$ & 2 & 72.99 & $<0.001$ & 2 & 15.91 & $<0.001$ \\
\hline Temperature difference & 1 & 13.08 & $<0.001$ & 1 & 9.29 & 0.002 & 1 & 5.48 & 0.019 \\
\hline $\begin{array}{l}\text { Breeding-system treatment } \times \text { tem- } \\
\text { perature difference }\end{array}$ & 2 & 9.12 & 0.010 & 2 & 3.66 & 0.160 & 2 & 1.18 & 0.554 \\
\hline Growth chamber & & & 0.463 & & & 0.717 & & & 0.008 \\
\hline Population & & & 0.688 & & & 4.232 & & & 0.019 \\
\hline Seed family & & & $<0.001$ & & & 0.000 & & & 0.006 \\
\hline Plant ID & & & $<0.001$ & & & 3.743 & & & 0.008 \\
\hline Residuals & & & 0.868 & & & 6.844 & & & 0.033 \\
\hline
\end{tabular}

Random variables include growth chamber, population, seed family and plant ID. Standard deviations are provided for random variables a negative response of flower size [e.g., in Epilobium angustifolium, (Carroll et al. 2001); in Lobelia siphilitica, (Caruso 2006)] and anther-stigma separation [e.g., in Lythrum salicaria, (Mal and Lovett-Doust 2005)] to drought. By specifically focusing on temperature changes, our study advances our understanding of the effects of different climate change components on plant reproduction.

The effect of increased temperature on flower size has been documented in some horticultural plants. For example, Pearson et al. (1995) found a decrease in flower size with increasing temperature in pansy Viola $\times$ wittrockiana. Among the few previous studies that have assessed plasticity in floral traits favoring selfing under temperature changes in wild plants, Vogler et al. (1999) found that corolla size of Campanula rapunculoides decreased in a hotter environment. It is likely that increased temperature affects molecular and physiological processes during flower development (Beauzamy et al. 2014), but the exact mechanisms require further study. As the measured floral traits in our study responded differently to temperature change, it could be that flower size and anther-stigma separation are controlled by different regulatory genes and developmental mechanisms.

Previous studies on plastic changes in floral traits associated with autonomous selfing had inconsistent results. In the high-elevation plant Aquilegia coerulea, plants grown in a warm room had shorter anthers and stigmas than those in a cold room, but the resulting impact on anther-stigma separation differed among populations (Van Etten and Brunet 2013). Opedal et al. (2016) showed that the Neotropical vine Dalechampia scandens responded rapidly to drought by reducing bract area, but they did not find a consistent effect of drought on the anther-stigma separation and on autonomous selfing across the four populations they studied. In M. guttatus, Arathi and Kelly (2004) suggests that autonomous selfing is largely influenced by the morphology of the lower corolla lip. Most other studies, however, suggest that small flowers and small anther-stigma separation are associated with high selfing rates in M. guttatus (Carr and Fenster 1994; Fenster and Ritland 1994; Ritland and Ritland 1989; van Kleunen and Ritland 2004). On the other hand, Ivey and Carr (2005) found that herbivory by spittlebugs increased both anther-stigma separation and selfing rates in $M$. guttatus. If changes in floral traits reduce attractiveness to pollinators but the capacity for autonomous selfing does not increase, the effect of increased temperature might have strong negative implications on plant reproduction and persistence under climate change.

The reduction in floral traits involved in attraction of pollinators induced by temperature increase found in this study may lead to reduced flower-visitation rates and limited opportunity for cross-pollination. Similarly, Mu et al. (2015) found that long-term experimental increased temperature reduced nectar production in the Tibetan alpine species Saussurea nigrescens, and concluded that climate change will affect plant-pollinator interactions. Martin (2004) showed that small flowers of $M$. guttatus received fewer flower visits than large flowers. Furthermore, it has been shown that many floral traits of $M$. guttatus show heritable variation in natural populations (van Kleunen and Ritland 2004), and that in response to pollinator loss, M. guttatus showed a rapid evolution of reproductive characteristics toward increased selfing as a result of selection after five generations (Bodbyl Roels and Kelly 2011). Nevertheless, if increased temperature and frequent high temperature events hamper flower development and seed production, even if not many generations would be needed, the persistence of a sufficient number of generations to allow such a rapid evolution to occur might be unlikely.

Alternatively, the reduced floral size of Mimulus guttatus might make them more attractive to pollinators other than their usual bee pollinators. Disruption of plant-pollinator interactions have been suggested to be mitigated by the flexibility of pollination networks (Memmott et al. 2007). If smaller-bodied pollinators become more suitable 

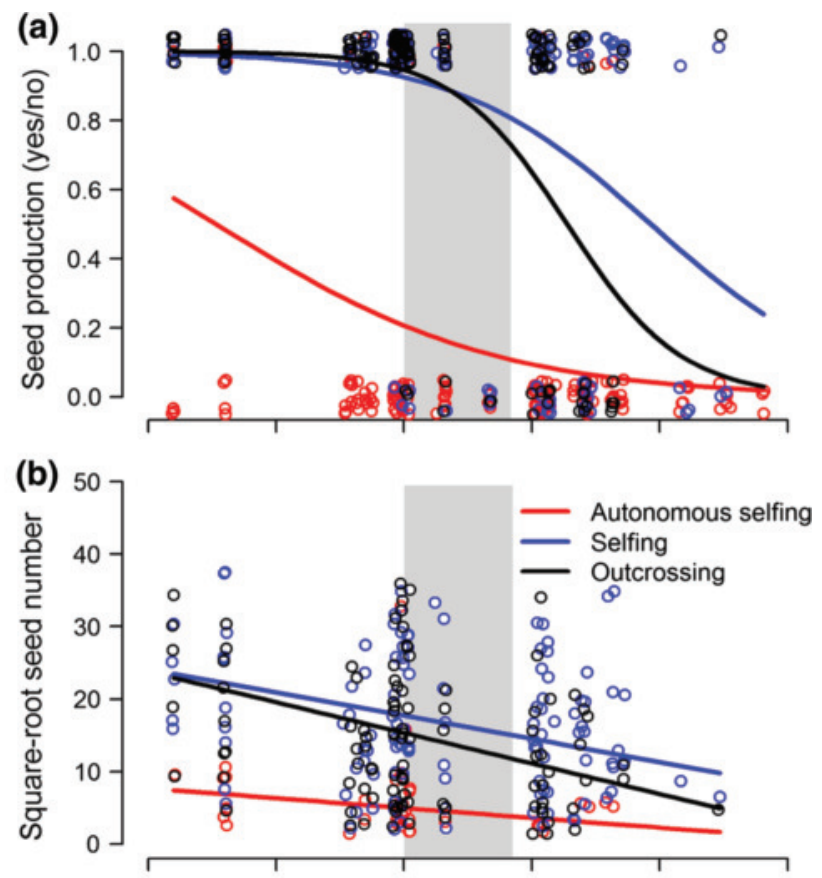

(c)

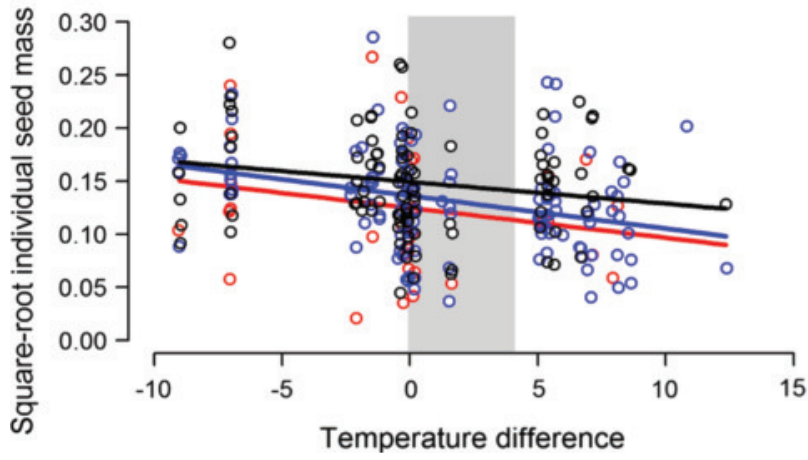

Fig. 3 Results of a logistic regression and two linear mixed models testing how a seed production (yes/no), b the square root seed number and $\mathbf{c}$ the square root individual seed mass $(\mathrm{mg})$ depend on the temperature difference between the experimental test temperature and the home temperature, breeding-system treatment, and the interaction between the temperature difference and breeding-system treatment across populations. Shaded areas represent up to $4{ }^{\circ} \mathrm{C}$ temperature increase as predicted by the IPCC for 2100 for the new floral traits, pollinator shifts might occur, and the flowers might also adapt to these new pollinators (Gervasi and Schiestl 2017). Nevertheless, such shifts depend on the availability of the potential pollinator and thus on a sufficiently high species diversity in the community (KaiserBunbury et al. 2010).

\section{Seed production decreased when temperature increased}

Besides the reduction in flower size, we also found that increased temperature strongly reduced overall seed production (Fig. 3). This is in line with previous findings showing reduced ovary size and number of ovules, and thus reduced maximum number of seeds per fruit capsule in smaller flowers (Fishman and Willis 2008). A reduced likelihood for seed production, seed number and individual seed mass under warmer conditions could be due to negative effects of temperature at different developmental stages during the reproductive process. Temperature stress can affect pollen development and reduce pollen viability, pollen germination and pollen-tube growth, leading to a reduced seed production in many crop plants (reviewed in Hedhly et al. 2009). Temperature stress can also shorten the period of stigma receptivity, leading to reduced pollen adhesion, germination and penetration (Hedhly et al. 2003). Furthermore, increased temperature can accelerate the degradation of stigma and ovules and the inhibition of pollen-tube growth (Hedhly et al. 2009). Therefore, increased temperatures in our study might have reduced the number of ovules as well as the likelihood of ovule fertilization. Because individual seed mass decreased when temperature increased (Fig. 2c), temperature stress might also have affected embryo development (Egli and Wardlaw 1980; Hedhly et al. 2009). Whether low seed development is associated with reduced seed viability and low germination rates remains to be tested. Negative effects of increased temperatures on seed production of crop plants have been relatively well documented (Hedhly et al. 2009). Here, by providing such evidence for a wild plant species,

Table 3 Posterior distribution of the parameter means (2.5\% quantile, 97.5\% quantile) of a zero-and-one-inflated beta regression testing how the index of autonomous selfing (ASI) in Mimulus guttatus is influenced by the temperature difference between the experimental test temperature and the home temperature

\begin{tabular}{lcccc}
\hline Explanatory and random variables & Probability of ASI $=0$ & $\begin{array}{l}\text { Mean of the beta regression } \\
(0<\text { ASI }<1)\end{array}$ & $\begin{array}{l}\text { Sum of the } \\
\text { shape param- } \\
\text { eters }\end{array}$ & Probability of ASI =1 \\
\hline Intercept & $1.028(0.562,1.530)$ & $-1.736(-2.858,-0.700)$ & $1.491(0.782$, & $-2.590(-4.641,-1.132)$ \\
& $0.186(0.074,0.309)$ & $0.115(-0.041,0.271)$ & & $-0.282(-0.613,0.001)$ \\
$\begin{array}{l}\text { Temperature difference } \\
\text { Growth chamber }\end{array}$ & $1.382(0.001,7.950)$ & & & \\
\hline
\end{tabular}

Explanatory variable includes temperature difference. Different components of the models include probability of ASI $=0$, mean of the beta regression $(0<\mathrm{ASI}<1)$, sum of the shape parameters and probability of ASI $=1$. Random variable includes growth chamber 
Table 4 Posterior distribution of the parameter means $(2.5 \%$ quantile, $97.5 \%$ quantile) of three zero-and-one-inflated beta regressions testing how the index of autonomous selfing (ASI) in Mimulus guttatus is influenced by floral traits

\begin{tabular}{lccc}
\hline & Flower length & Flower width & Anther-stigma separation \\
\hline Probability of ASI $=0$ & & & \\
Intercept & $7.064(3.941,10.595)$ & $9.324(5.587,13.630)$ & $0.941(-0.298,2.217)$ \\
Floral traits & $-0.189(-0.295,-0.094)$ & $-0.283(-0.422,-0.161)$ & $0.012(-0.279,0.310)$ \\
Mean of the beta regression $(0<$ ASI $<1)$ & & \\
Intercept & $-3.053(-6.937,0.639)$ & $-2.179(-5.764,1.256)$ & $0.024(-1.413,1.260)$ \\
Floral traits & $0.036(-0.061,0.134)$ & $0.014(-0.087,0.117)$ & $-0.527(-0.833,-0.203)$ \\
Sum of the shape parameters & & $1.307(0.573,1.962)$ & $1.963(1.156,2.668)$ \\
Intercept & $1.368(0.623,2.023)$ & & \\
Probability of ASI = & & & \\
Intercept & $4.704(-1.951,12.306)$ & $-1.821(-10.243,5.653)$ & $-1.140(-4.449,1.796)$ \\
Floral traits & $-0.190(-0.431,0.010)$ & $0.007(-0.228,0.255)$ & $-0.115(-0.882,0.653)$ \\
Growth chamber & $1.539(0.002,8.849)$ & $1.383(0.002,8.085)$ & $0.950(0.000,4.656)$ \\
\hline
\end{tabular}

Explanatory variable includes flower length, flower width and anther-stigma separation, respectively. Different components of the models include probability of ASI $=0$, mean of the beta regression $(0<\mathrm{ASI}<1)$, sum of the shape parameters and probability of ASI $=1$. Random variable includes growth chamber our study advances our understanding of the potential impacts of climate change components on the reproduction of both wild and crop plants.

\section{Conclusion}

The range of temperature change created in our study was large, including an extreme increase in temperature of $+14{ }^{\circ} \mathrm{C}$ for one of the populations. This is far outside the range of average temperature increases forecasted by different climate models and scenarios (IPCC 2013). However, climate change is not only characterized by an increase in the average temperature, but there will also be an increase in extreme weather events (IPCC 2013). Even if plant responses to climate change in natural environments can be more complex than predictions from experiments suggest (Parmesan and Hanley 2015), our temperature change experiment suggests strong negative effects of increased temperature and extreme temperature events on the reproduction and thus the long-term persistence of M. guttatus. On the other hand, the remarkable drop in fitness suggested by a steep decrease in seed production with temperature increase might suggest strong selection. If $M$. guttatus can rapidly evolve shifts in breeding systems (Bodbyl Roels and Kelly 2011), it could be that, instead of plastic changes, the plants will respond to climate change with a rapid evolution of floral traits and shifts in selfing ability. Yet, temperature changes may co-vary with other environmental factors such as water availability and soil $\mathrm{pH}$, which might have direct or indirect effects on plant reproduction and persistence. Future studies should test whether other climate change components such as changes in precipitation, an increase in atmospheric $\mathrm{CO}_{2}$ concentrations, an increase in nitrogen deposition, and the interactive effects of different components add to the detrimental effects of climate warming found in this study.

Acknowledgements We thank Otmar Ficht and Claudia Martin for their help in sowing the seeds, Heinz Vahlenkamp for taking care of the growth chambers, Marc Stift for helpful discussions, and Vanessa Pasqualetto for her help in weighing and counting seeds. M.R. thanks the German Research Foundation DFG for funding (RA 3009/1-1).

Author contribution statement MR, LF and MvK designed the study, LF conducted the experiment, MR, LF and MvK analyzed the data, and MR wrote the manuscript with input from LF and MvK.

\section{Compliance with ethical standards}

Conflict of interest The authors declare that they have no conflict of interest.

\section{References}

Aarssen LW (2000) Why are most selfers annuals? A new hypothesis for the fitness benefit of selfing. Oikos 89:606-612. https://doi.org /10.1034/j.1600-0706.2000.890321.x

Arathi H, Kelly JK (2004) Corolla morphology facilitates both autogamy and bumblebee pollination in Mimulus guttatus. Int J Plant Sci 165:1039-1045. https://doi.org/10.1086/423876

Ascher PD, Peloquin S (1966) Influence of temperature on incompatible and compatible pollen tube growth in Lilium longiflorum. Can J Genet Cytol 8:661-664. https://doi.org/10.1139/g66-081

Bates D, Maechler M, Bolker B, Walker S (2015) Fitting linear mixedeffects models using lme4. J Stat Softw 67:1-48

Beauzamy L, Nakayama N, Boudaoud A (2014) Flowers under pressure: ins and outs of turgor regulation in development. Ann Bot 114:1517-1533. https://doi.org/10.1093/aob/mcu187

Bodbyl Roels SA, Kelly JK (2011) Rapid evolution caused by pollinator loss in Mimulus guttatus. Evolution 65:2541-2552. https://doi. org/10.1111/j.1558-5646.2011.01326.x

Brys R, Geens B, Beeckman T, Jacquemyn H (2013) Differences in dichogamy and herkogamy contribute to higher selfing in contrasting environments in the annual Blackstonia perfoliata 
(Gentianaceae). Ann Bot 111:651-661. https://doi.org/10.1093/ aob/mct031

Burkle LA, Marlin JC, Knight TM (2013) Plant-pollinator interactions over 120 years: loss of species, co-occurrence, and function. Science 339:1611-1615. https://doi.org/10.1126/scien ce. 1232728

Carr DE, Fenster CB (1994) Levels of genetic variation and covariation for Mimulus (Scrophulariaceae) floral traits. Heredity 72:606-618

Carroll AB, Pallardy SG, Galen C (2001) Drought stress, plant water status, and floral trait expression in fireweed, Epilobium angustifolium (Onagraceae). Am J Bot 88:438-446. https://doi. org/10.2307/2657108

Caruso CM (2006) Plasticity of inflorescence traits in Lobelia siphilitica (Lobeliaceae) in response to soil water availability. Am J Bot 93:531-538. https://doi.org/10.3732/ajb.93.4.531

Chevin L-M, Hoffmann AA (2017) Evolution of phenotypic plasticity in extreme environments. Philos Trans R Soc B Biol Sci. https:// doi.org/10.1098/rstb.2016.0138

Cohen JM, Lajeunesse MJ, Rohr JR (2018) A global synthesis of animal phenological responses to climate change. Nat Clim Change 8:224-228. https://doi.org/10.1038/s41558-018-0067-3

Colegrave N, Ruxton GD (2017) Using biological insight and pragmatism when thinking about pseudoreplication. Trends Ecol Evol 33:28-35. https://doi.org/10.1016/j.tree.2017.10.007

Dole JA (1992) Reproductive assurance mechanisms in three taxa of the Mimulus guttatus complex (Scrophulariaceae). Am J Bot 79:650-659. https://doi.org/10.1002/j.1537-2197.1992.tb14607.x

Eckert CG, Ozimec B, Herlihy CR, Griffin CA, Routley MB (2009) Floral morphology mediates temporal variation in the mating system of a self-compatible plant. Ecology 90:1540-1548. https:// doi.org/10.1890/08-1063.1

Eckert CG et al (2010) Plant mating systems in a changing world. Trends Ecol Evol 25:35-43. https://doi.org/10.1016/j. tree.2009.06.013

Egli D, Wardlaw I (1980) Temperature response of seed growth characteristics of soybeans. Agron J 72:560-564. https://doi. org/10.2134/agronj1980.00021962007200030036x

Elle E, Hare J (2002) Environmentally induced variation in floral traits affects the mating system in Datura wrightii. Funct Ecol 16:7988. https://doi.org/10.1046/j.0269-8463.2001.00599.x

Evans ME, Hearn DJ, Theiss KE, Cranston K, Holsinger KE, Donoghue MJ (2011) Extreme environments select for reproductive assurance: evidence from evening primroses (Oenothera). New Phytol 191:555-563. https://doi.org/10.1111/j.1469-8137.2011.03697.x

Fenster CB, Ritland K (1994) Evidence for natural selection on mating system in Mimulus (Scrophulariaceae). Int J Plant Sci 155:588596. https://doi.org/10.1086/297197

Fishman L, Willis JH (2008) Pollen limitation and natural selection on floral characters in the yellow monkeyflower, Мітиlus guttatus. New Phytol 177:802-810. https://doi.org/10.111 1/j.1469-8137.2007.02265.x

Gervasi DD, Schiestl FP (2017) Real-time divergent evolution in plants driven by pollinators. Nat Commun 8:14691. https://doi. org/10.1038/ncomms 14691

Ghalambor CK, McKay JK, Carroll SP, Reznick DN (2007) Adaptive versus non-adaptive phenotypic plasticity and the potential for contemporary adaptation in new environments. Funct Ecol 21:394-407. https://doi.org/10.1111/j.1365-2435.2007.01283.x

Hedhly A, Hormaza J, Herrero M (2003) The effect of temperature on stigmatic receptivity in sweet cherry (Prunus avium L.). Plant Cell Environ 26:1673-1680. https://doi.org/10.104 6/j.1365-3040.2003.01085.x

Hedhly A, Hormaza JI, Herrero M (2009) Global warming and sexual plant reproduction. Trends Plant Sci 14:30-36. https://doi. org/10.1016/j.tplants.2008.11.001
Herlihy CR, Eckert CG (2002) Genetic cost of reproductive assurance in a self-fertilizing plant. Nature 416:320-323. https://doi. org $/ 10.1038 / 416320$ a

IPCC (2013) Climate change 2013: the physical science basis. In: Stocker TF, Qin D, Plattner G-K, Tignor M, Allen SK, Boschung J, Nauels A, Xia Y, Bex V, Midgley PM (eds) Contribution of working group I to the fifth assessment report of the intergovernmental panel on climate change. Cambridge University Press, Cambridge/New York

IPCC (2014) Climate change 2014: synthesis report. In: Core Writing Team, Pachauri RK, Meyer LA (eds) Contribution of working groups I, II and III to the fifth assessment report of the intergovernmental panel on climate change. IPCC, Geneva, Switzerland

Ivey CT, Carr DE (2005) Effects of herbivory and inbreeding on the pollinators and mating system of Mimulus guttatus (Phrymaceae). Am J Bot 92:1641-1649. https://doi.org/10.3732/ajb.92.10.1641

Ivey CT, Carr DE (2011) Tests for the joint evolution of mating system and drought escape in Mimulus. Ann Bot 109:583-598. https:// doi.org/10.1093/aob/mcr160

Jones N, Husband B, MacDougall A (2013) Reproductive system of a mixed-mating plant responds to climate perturbation by increased selfing. Proc R Soc Lond B Biol Sci 280:20131336. https://doi. org/10.1098/rspb.2013.1336

Kaiser-Bunbury CN, Muff S, Memmott J, Müller CB, Caflisch A (2010) The robustness of pollination networks to the loss of species and interactions: a quantitative approach incorporating pollinator behaviour. Ecol Lett 13:442-452. https://doi.org/10.111 1/j.1461-0248.2009.01437.x

Kalisz S, Vogler DW, Hanley KM (2004) Context-dependent autonomous self-fertilization yields reproductive assurance and mixed mating. Nature 430:884-887. https://doi.org/10.1038/nature02776

Kay KM, Picklum DA (2013) Drought alters the expression of mating system traits in two species of Clarkia. Evol Ecol 27:899-910. https://doi.org/10.1007/s10682-013-9630-6

Kearns CA, Inouye DW (1993) Techniques for pollination biologists. University Press of Colorado, Niwot

Koski MH, Kuo L, Niedermaier KM, Galloway LF (2018) Timing is everything: dichogamy and pollen germinability underlie variation in autonomous selfing among populations. Am J Bot 105:241248. https://doi.org/10.1002/ajb2.1025

Leclerc-Potvin C, Ritland K (1994) Modes of self-fertilization in Mimulus guttatus (Scrophulariaceae): a field experiment. Am J Bot 81:199-205. https://doi.org/10.1002/j.1537-2197.1994.tb15430.x

Leibman L, Rowe A, Koski MH, Galloway LF (2018) Populations with greater flexibility in floral traits modify mating system in response to the pollinator environment. Funct Ecol 32:1457-1466. https:// doi.org/10.1111/1365-2435.13093

Lekberg Y, Roskilly B, Hendrick MF, Zabinski CA, Barr CM, Fishman L (2012) Phenotypic and genetic differentiation among yellow monkeyflower populations from thermal and non-thermal soils in Yellowstone National Park. Oecologia 170:111-122. https:// doi.org/10.1007/s00442-012-2297-9

Levin DA (2010) Environment-enhanced self-fertilization: implications for niche shifts in adjacent populations. J Ecol 98:1276-1283. https://doi.org/10.1111/j.1365-2745.2010.01715.x

Liu F, Eugenio EC (2018) A review and comparison of Bayesian and likelihood-based inferences in beta regression and zero-or-oneinflated beta regression. Stat Methods Med Res 27:1024-1044. https://doi.org/10.1177/0962280216650699

Liu F, Kong Y (2015) zoib: an R package for bayesian inference for beta regression and zero/one inflated beta regression. RJ 7:34-51

Lloyd DG, Schoen DJ (1992) Self-and cross-fertilization in plants. I. Functional dimensions. Int J Plant Sci 153:358-369. https://doi. org/10.1086/297040

Mal TK, Lovett-Doust J (2005) Phenotypic plasticity in vegetative and reproductive traits in an invasive weed, Lythrum salicaria 
(Lythraceae), in response to soil moisture. Am J Bot 92:819-825. https://doi.org/10.3732/ajb.92.5.819

Martin NH (2004) Flower size preferences of the honeybee (Apis mellifera) foraging on Mimulus guttatus (Scrophulariaceae). Evol Ecol Res 6:777-782

Memmott J, Craze PG, Waser NM, Price MV (2007) Global warming and the disruption of plant-pollinator interactions. Ecol Lett 10:710-717. https://doi.org/10.1111/j.1461-0248.2007.01061.x

$\mathrm{Mu} \mathrm{J}$ et al (2015) Artificial asymmetric warming reduces nectar yield in a Tibetan alpine species of Asteraceae. Ann Bot 116:899-906. https://doi.org/10.1093/aob/mcv042

Nicotra AB et al (2010) Plant phenotypic plasticity in a changing climate. Trends Plant Sci 15:684-692. https://doi.org/10.1016/j.tplan ts. 2010.09 .008

Opedal ØH, Listemann J, Albertsen E, Armbruster WS, Pélabon C (2016) Multiple effects of drought on pollination and mating-system traits in Dalechampia scandens. Int J Plant Sci 177:682-693. https://doi.org/10.1086/687985

Parmesan C (2006) Ecological and evolutionary responses to recent climate change. Annu Rev Ecol Evol Syst 37:637-669. https:// doi.org/10.1146/annurev.ecolsys.37.091305.110100

Parmesan C, Hanley ME (2015) Plants and climate change: complexities and surprises. Ann Bot 116:849-864. https://doi.org/10.1093/ aob/mcv169

Parmesan C, Yohe G (2003) A globally coherent fingerprint of climate change impacts across natural systems. Nature 421:37-42. https ://doi.org/10.1038/nature01286

Pearson S, Parker A, Adams SR, Hadley P, May DR (1995) The effects of temperature on the flower size of pansy (Viola $\mathrm{x}$ wittrockiana Gams.). J Hortic Sci 70:183-190. https://doi.org/10.1080/14620 316.1995.11515287

R Core Team (2012) A language and environment for statistical computing. R Foundation for Statistical Computing, Vienna

Razanajatovo M, Föhr C, van Kleunen M, Fischer M (2018) Phenological shifts and flower visitation of 185 lowland and alpine species in a lowland botanical garden. Alpine Botany 128:23-33. https:// doi.org/10.1007/s00035-018-0201-x

Ritland C, Ritland K (1989) Variation of sex allocation among eight taxa of the Mimulus guttatus species complex (Scrophulariaceae). Am J Bot 76:1731-1739. https://doi. org/10.1002/j.1537-2197.1989.tb15163.x

Robertson AW, Mountjoy C, Faulkner BE, Roberts MV, Macnair MR (1999) Bumble bee selection of Mimulus guttatus flowers: the effects of pollen quality and reward depletion. Ecology 80:25942606. https://doi.org/10.1890/0012-9658(1999)080\%5b259 4:bbsomg\% $5 \mathrm{~d} 2.0 . \mathrm{co} ; 2$

Sheridan JA, Bickford D (2011) Shrinking body size as an ecological response to climate change. Nat Clim Change 1:401-406. https:// doi.org/10.1038/nclimate1259

Sicard A, Lenhard M (2011) The selfing syndrome: a model for studying the genetic and evolutionary basis of morphological adaptation in plants. Ann Bot 107:1433-1443. https://doi.org/10.1093/ aob/mcr023
Spigler RB, Kalisz S (2013) Phenotypic plasticity in mating-system traits in the annual Collinsia verna. Botany 91:597-604. https:// doi.org/10.1139/cjb-2012-0227

Travers SE, Mena-Ali J, Stephenson AG (2004) Plasticity in the selfincompatibility system of Solanum carolinense. Plant Species Biol 19:127-135. https://doi.org/10.1111/j.1442-1984.2004.00109.x

Vallejo-Marín M, Barrett SC (2009) Modification of flower architecture during early stages in the evolution of self-fertilization. Ann Bot 103:951-962. https://doi.org/10.1093/aob/mcp015

Van Etten ML, Brunet J (2013) The impact of global warming on floral traits that affect the selfing rate in a high-altitude plant. Int J Plant Sci 174:1099-1108. https://doi.org/10.1086/671805

van Kleunen M (2007) Adaptive genetic differentiation in life-history traits between populations of Mimulus guttatus with annual and perennial life-cycles. Evol Ecol 21:185-199. https://doi. org/10.1007/s10682-006-0019-7

van Kleunen M, Ritland K (2004) Predicting evolution of floral traits associated with mating system in a natural plant population. J Evol Biol 17:1389-1399. https://doi.org/10.111 1/j.1420-9101.2004.00787.x

van Kleunen M, Dawson W, Bossdorf O, Fischer M (2014) The more the merrier: multi-species experiments in ecology. Basic Appl Ecol 15:1-9. https://doi.org/10.1016/j.baae.2013.10.006

van Kleunen M, Röckle M, Stift M (2015) Admixture between native and invasive populations may increase invasiveness of Мітиlus guttatus. Proc R Soc B Biol Sci 282:20151487. https://doi. org/10.1098/rspb.2015.1487

van Kleunen M, Pyšek P, Dawson W, Essl F, Kreft H, Pergl J, Weigelt P, Stein A, Dullinger S, König C, Lenzner B, Maurel N, Moser D, Seebens H, Kartesz J, Nishino M, Aleksanyan A, Ansong M, Antonova LA, Barcelona JF, Breckle SW, Brundu G, Cabezas FJ, Cárdenas D, Cárdenas-Toro J, Castano N, Chacón E, Chatelain C, Conn B, de Sá Dechoum M, Dufour-Dror JM, Ebel AL, Figueiredo E, Fragman-Sapir O, Fuentes N, Groom QJ, Henderson L, Inderjit Jogan N, Krestov P, Kupriyanov A, Masciadri S, Meerman J, Morozova O, Nickrent D, Nowak A, Patzelt A, Pelser PB, Shu WS, Thomas J, Uludag A, Velayos M, Verkhosina A, Villasenor JL, Weber E, Wieringa JJ, Yazlik A, Zeddam A, Zykova E, Winter M (2019) The Global Naturalized Alien Flora (GloNAF) database. Ecology 100:e02542. https://doi.org/10.1002/ecy.2542

Vogler DW, Das C, Stephenson AG (1998) Phenotypic plasticity in the expression of self-incompatibility in Campanula rapunculoides. Heredity 81:546-555. https://doi.org/10.104 6/j.1365-2540.1998.00417.x

Vogler DW, Peretz S, Stephenson AG (1999) Floral plasticity in an iteroparous plant: the interactive effects of genotype, environment, and ontogeny in Campanula rapunculoides (Campanulaceae). Am J Bot 86:482-494. https://doi.org/10.2307/2656809

Zuur A, Ieno E, Walker N, Saveliev A, Smith G (2009) Mixed effects models and extensions in ecology with R. Springer, New York 